\title{
AC 2007-2085: DEVELOPING EDUCATIONAL SOFTWARE IN AN UNDERGRADUATE LAB ? SERVING EDUCATION ON TWO FRONTS AT VRUPL
}

John Bell, University of Illinois-Chicago 


\title{
Developing Educational Software in an Undergraduate Lab - Serving Education on Two Fronts at VRUPL
}

\begin{abstract}
Educational software can have a profound and widespread positive impact on the world, particularly if it is made freely available and widely distributed. At the same time, providing a laboratory where undergraduate students can work on large complex software projects beyond the scope of ordinary homework assignments can provide immeasurable benefits to those students by providing them opportunities to work together with others to meet long-term goals. This paper will discuss how one such laboratory, the Virtual Reality Undergraduate Project Laboratory, VRUPL, serves education on two fronts by developing large-scale virtual reality educational simulations in an undergraduate research laboratory, and distributes the resulting products free of charge.
\end{abstract}

\section{PEDAGOGICAL BACKGROUND}

The work presented in this paper is based upon three important pedagogical foundations:

1. Dale Edgar's Cone of Learning: Students retain more knowledge for a longer period of time when the information is presented through multiple delivery channels, particularly when one or more of those channels involves active participation. In 1969, Dale Edgar conducted a now famous study in which students were taught using a variety of different teaching mechanisms, and tested two weeks later to see how much they had retained after that time[1]. He found that after 2 weeks we tend to remember only $10 \%$ of what we read, $20 \%$ of what we hear, and $30 \%$ of what we see, but up to $50 \%$ of what we both hear AND see. One of the benefits of educational simulations is that they reinforce material that students have already received through assigned reading or classroom lectures by adding an additional delivery channel for the material.

In addition to passive delivery channels, things get even better when active participation is included - Edgar found that we retain up to $70 \%$ of what we say and up to $90 \%$ of what we say and do. The deeper and more active a student's participation, the better their retention. Doing the real thing is better than watching a simulation, which is still better than merely hearing or reading about it. In terms of the work of this project specifically, virtual reality is designed to produce a very immersive, participatory experience, much more active than a textbook, and the students who are developing the software also have much more active involvement than traditional reading and studying.

2. Learning and Teaching Styles: The learning methods that are most effective for any particular learner varies with the individual, and determines their personal learning style. For example, some students learn very well through verbal communication channels such as textbooks and traditional lectures, while others are more visually oriented and need to see pictures, diagrams, movies or other visual representations for most effective learning. There are also corresponding teaching styles, and when the latter does not match well with the former, it can be difficult for that particular student to learn. 
Felder and Silverman addressed learning and teaching styles, and developed five dimensions along which they are defined [2, 3]. In particular, virtual reality based educational simulations specifically address the needs of the following types of learners:

- Visual learners learn best from pictures, diagrams, videos, and other visual input. VR is inherently full of 3D computer graphics which directly addresses the needs of visual learners.

- Global learners need to see the big picture and how all the parts fit together before any of the individual parts make sense, but often get more understanding of the overall subject once all the pieces are in place. VR helps with this because it is possible to see all of the components and issues of a complex situation and how they inter-relate, as opposed to focusing narrowly on one small sub-topic at a time.

- Active learners learn best when they can actively participate, in a discussion, experiment, or play. VR is inherently an interactive environment, in which students actively manipulate objects and observe the reactions of the overall system.

- Sensory learners learn best through sensory input, such as sights, sounds, and smells, as opposed to intuitive learners who are better suited to handle internal concepts, thoughts, and ideas. VR appeals to the sensory learners who are presented with dynamic 3D sights, spatially located sounds, and possibly haptic, tactile, olfactory, or other sensory feedback.

- Inductive learners observe phenomenon and then infer the underlying principles that must explain them, as opposed to deductive learners who start with fundamental theories and then deduce how they apply to practical applications. Humans ( e.g. babies ) tend to naturally learn inductively, whereas classroom presentations traditionally take a more deductive approach. VR addresses the needs of inductive learners by allowing them to directly observe the effects caused by their actions.

Felder and Silverman conclude that teaching methods in engineering typically fail to address the learning styles of many engineering students, who tend to be visual, active, sensory, inductive, and often global, while traditional methods tend to be verbal, passive, intuitive, deductive, and sequential. VR addresses this gap, by delivering an experience that is highly visual and active, and which gives global learners an opportunity to see the overall picture of the subject in a larger context.

3. Experiential Learning: In addition to the benefits of delivering education through multiple delivery channels, and addressing students' optimal learning styles, Kolb found additional benefits to be gained by learning through experience. [4] Someone reading about a house fire or an auto accident in the newspaper, for example, will only remember the details for a short while; Someone who experienced the fire or the auto accident (and survived), however, will remember that experience for the rest of their lives. 
VR provides the opportunity to deliver educational experiences that would not be possible through any other means, such as exploring the microscopic pores of a catalyst pellet, entering a chemical reactor while it is operating, or surviving a laboratory explosion and repeating the experience in order to ascertain the cause of the explosion. ( Note: Virtual experiences will never compare to real experiences, and should not be used as a substitute for the latter when the latter is available. The authors do not promote replacing traditional hands-on experiments with virtual ones, but rather supplementing them with experiences that are too hazardous, inaccessible, or otherwise impossible to achieve without simulation. )

In terms of the students developing the software, they also receive a much more experiential education, through the active participation in software development. The simulations developed for this project require at least one full semester and often more to complete, which provides the students with a much more significant project to work on than traditional classroom homework assignments.

\section{THE VRUPL LABORATORY}

This section describes the physical and human resources of the VRUPL lab, as well as how the lab operates.

\section{Physical Resources}

Physically the VRUPL lab is quite modest and inexpensive. It occupies two rooms, each of which is the size and configuration of a normal faculty office. Each room is equipped with two tables on which 4 monitor/keyboard sets are placed. The use of KVM switches allow for more than 8 computers to be connected to these 8 work stations, however in current practice only a few of the computers see regular use.

The computers in the VRUPL lab consist of three modern fast PCs with high speed dual-head graphics cards, three older PCs purchased when the lab was originally established, and a number of Silicon Graphics $\mathrm{O} 2$ workstations that were handed down to the lab when some of the university teaching labs were upgraded. In practice all current work occurs on the newer faster PCs, ( or on students' personal laptops or home computers. )

Special equipment in the VRUPL lab includes five sets of head-mounted displays of various types, a Polhemus electromagnetic head and hand tracker, a Logitech acoustic tracker, and CrystalEyes stereoscopic eyewear. The most recent addition to the lab is a pair of matched and synchronized projectors which provide for stereoscopic projection onto a wall-sized screen, using inexpensive and lightweight polarized glasses for comfortable stereoscopic viewing on a large scale. 

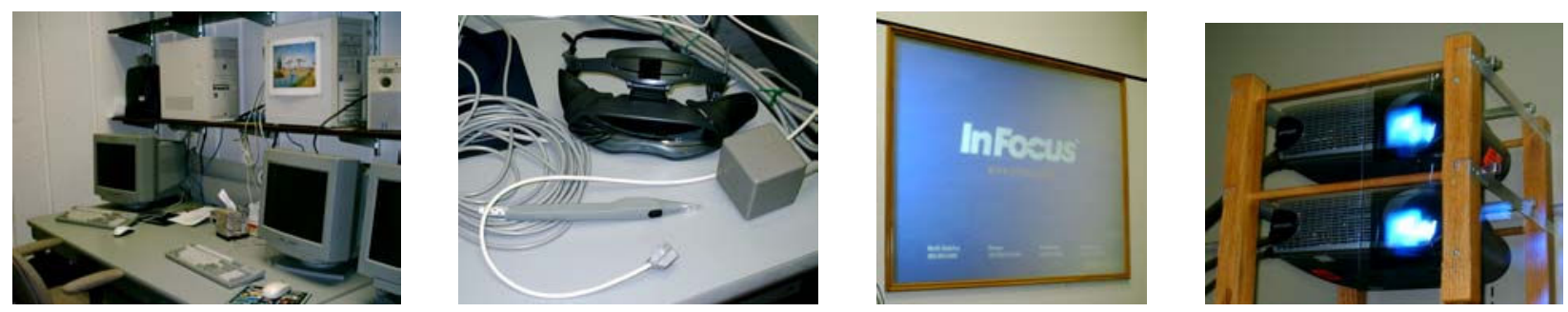

Figure 1 - Images from the VRUPL Lab

VRUPL is organized as a satellite to the much larger Electronic Visualization Laboratory, EVL, which is world-renowned in virtual reality, computer graphics, scientific visualization, ( immersive ) display technology, and high-speed networking. This arrangement gives VRUPL students access to advanced equipment such as the CAVETM[5], Immersadesks ${ }^{\mathrm{TM}}$ [6], and tiled displays, while keeping the undergraduates from disturbing the normal operation of graduate research activities.

\section{Human Resources}

The VRUPL lab is directed and managed by the author of this paper. More than 30 undergraduate students and five graduate students have been involved in VRUPL since its inception Currently there are four active VRUPL students, working on half a dozen different projects and subprojects, though there have been as many as a dozen students at a time in the past. Typically there will be some mix of new students and experienced students, which provides for good continuity and training opportunities. VRUPL is designed as an undergraduate laboratory, however several students have become so involved in their projects as undergrads that they have elected to continue on with them after they completed their bachelor's work and continued on for graduate studies, ( even though their work with VRUPL had nothing to do with their graduate program. ) Other students used their experience with VRUPL as a stepping stone, advancing on to the EVL lab when they commenced their graduate studies.

\section{Lab Operations}

VRUPL students work in the lab for one of three major incentives ( or combinations thereof) : Class credit, money, or just plain fun. And of course, everyone gets the opportunity to enhance their education, share an experience with other bright energetic minds, and play with all the cool toys. In terms of class credit, some students enroll in CS 398, special topics, and some are involved in VRUPL as an Honors College activity. VRUPL has had some funding from the National Science Foundation that has been used to provide some hourly student stipends, and VRUPL has also received some REU ( Research Experience for Undergraduates ) funding from the EVL lab. The students working just for fun generally have very full schedules, and do not want to add any additional commitments. Students who want to get paid by VRUPL must generally complete CS 398 first, both to get the necessary training and also to confirm their genuine interest in more than just a paycheck.

As far as training goes, VRUPL is fortunate to have about an equal mix of experienced and new students, so the new people generally learn from the old hands. In addition, the older students are generally being paid, and one of their specific job duties is to teach the new students. VRUPL also tends to attract bright independent self-starters, which helps a lot, because they do 
not generally require a great deal of training from the lab director. Logistically the director meets with each of the students at least once a week, generally in groups of two to four students working on the same or related projects, and generally for half-hour to hour meetings. CS 398 students are expected to work on a cohesive project for the duration of the term, and submit a term project report at the end of that time. Paid employees and students working just for fun and experience may have more variety in their activities.

\section{PRODUCT DESCRIPTION}

The VRUPL lab has worked on four major project areas, each of which is briefly listed here and then described in further detail in following sections:

1. Virtual Laboratory Accidents - A series of VR simulations of laboratory environments, leading to accidents if students do not follow all appropriate lab safety procedures.

2. Virtual Campus - A series of VR models of the local campus, for the benefit of foreign visitors to become acclimatized before their arrival.

3. The Holodeck - An immersive development environment in which students can develop their own virtual worlds.

4. Maintenance of Past Projects - A former project at another university produced a series of virtual chemical plants, which are now maintained and distributed through [ BLIND ].

\section{Virtual Lab Accidents}

The virtual lab accidents project was the founding cornerstone of the VRUPL lab ( including NSF funding ), and the area in which the most productivity has occurred. The basic premise behind this project area is that students will quickly forget long tedious lists of boring lab safety rules, however anyone who has ever experienced a real laboratory accident will remember that experience ( and hopefully learn from it ) for a much longer time. Simulated accidents are obviously not as memorable as true experiences, however they should still be more memorable and have a more long-lasting impact than simple written rules.

Part of the research goal for this project area was to experiment with different development platforms, in order to determine how to best implement educational virtual reality. It was also desired to address lab safety issues that were common across a broad spectrum of laboratory environments, and not restricted to a particular field or area of study. ( E.g. common to educational, research, and industrial / professional labs in chemistry, biology, medicine, physics, etc. ) As a result, simulations were developed for eight different accident scenarios implemented using about half a dozen different development platforms, including VRML, Java3D, WorldToolKit, WorldUp, and most recently the Half-Life game engine.

Of these, WorldToolKit was by far the most productive tool, with the added benefits of providing support for a wide variety of optional specialty hardware devices ( e.g. head-mounted displays ) and also of producing simulations for a wide variety of hardware platforms ( Windows, SGI, etc. ) with a simple re-compilation of the code ( and some slight reformatting of a few data files. ) The format of WorldToolKit was a $\mathrm{C}$ language library of methods pertaining 
to virtual reality software development, including support for special devices, loading up of models in many different file formats, overall running of the simulations, and controlling user interactivity and feedback.
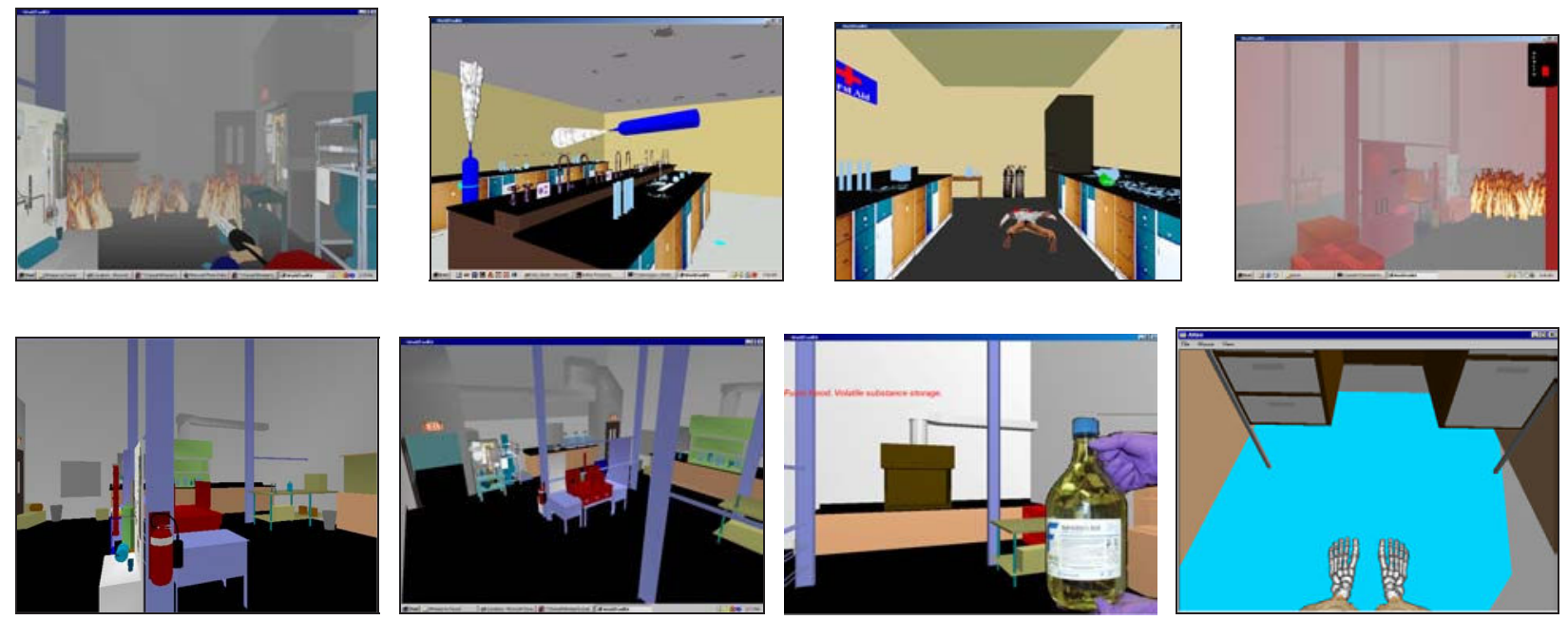

Figure 2 - Accident Simulations Developed Using WorldToolKit

WorldUp was a graphical front-end to WorldToolKit, which was supposed to be more userfriendly, but which did not work as well for us in practice. This may have been because the students were more predisposed to do raw programming using a library or possibly because the lab director was more familiar with WorldToolKit and therefore better able to provide training and guidance. VRML and Java3D were faddish, and resulted in only a few useful simulations.
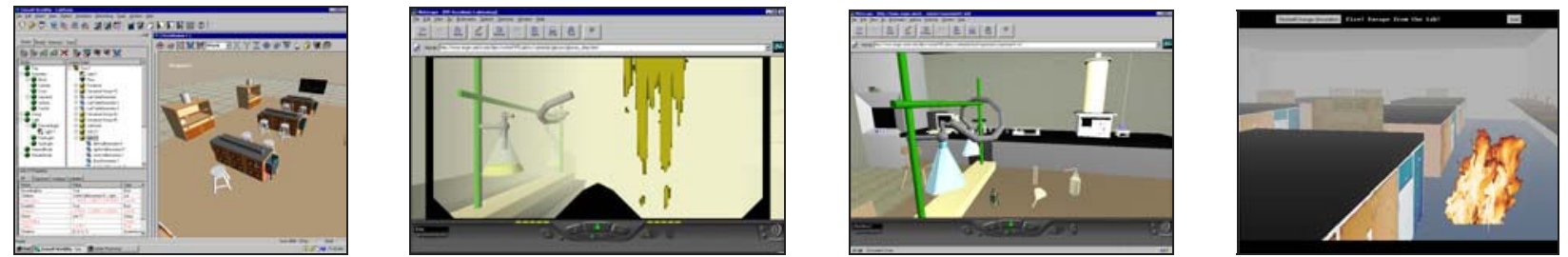

Figure 3 - Simulations Developed Using WorldUp, VRML( 2 images ), and Java3D.

Unfortunately, Sense8, the company that produced WorldToolKit has now gone out of business and so WorldToolKit is no longer supported. Although we do still have copies of the libraries, they do not work with the current versions of our other development systems, and furthermore are hardware-linked to particular systems serial numbers. As a result, we will try to maintain existing products developed under WorldToolKit as best as we can, but will no longer be producing any new materials with this platform, and will instead be working to port our existing applications to a more modern development platform. Specifically we have begun developing scenarios using the Half-Life game engine, and will continue to port new and existing scenarios to this new platform. ( One of the important lessons we have learned, and one of the key difficulties that we face now, is to try to predict the longevity of the development platform upon which a piece of work is based. ) 

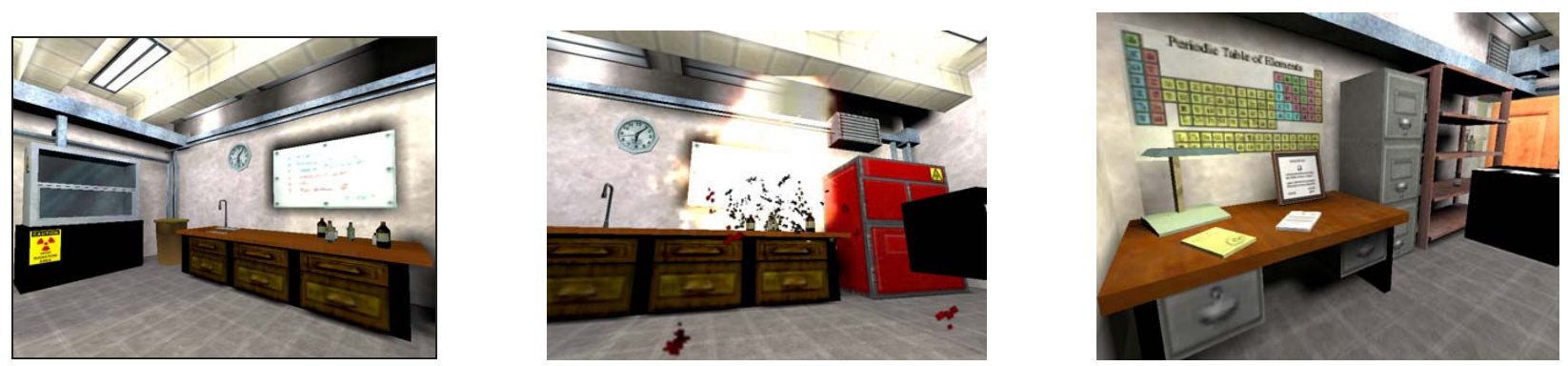

Figure 4 - Images from New Development Using Half-Life

\section{Virtual Campus}

Another project area under development in the VRUPL lab is a VR based simulation of the campus, initially as a campus overview and eventually modeling many individual buildings. This project benefits from the fact that the environment being modeled is close at hand for easy access to measurement and digital image capture, as well as providing interest to the students. ( And an almost limitless selection of potential projects, given the large number of buildings on campus and the fact that one small building or a few floors of a larger one is generally about right for a semester-long project for a single student. ) This project is considered "educational" in that it enables foreign visitors to learn their way around campus before ever leaving home, and of course the students developing the simulations learn a lot about 3D modeling, computer simulation, and many other aspects of computer graphics.
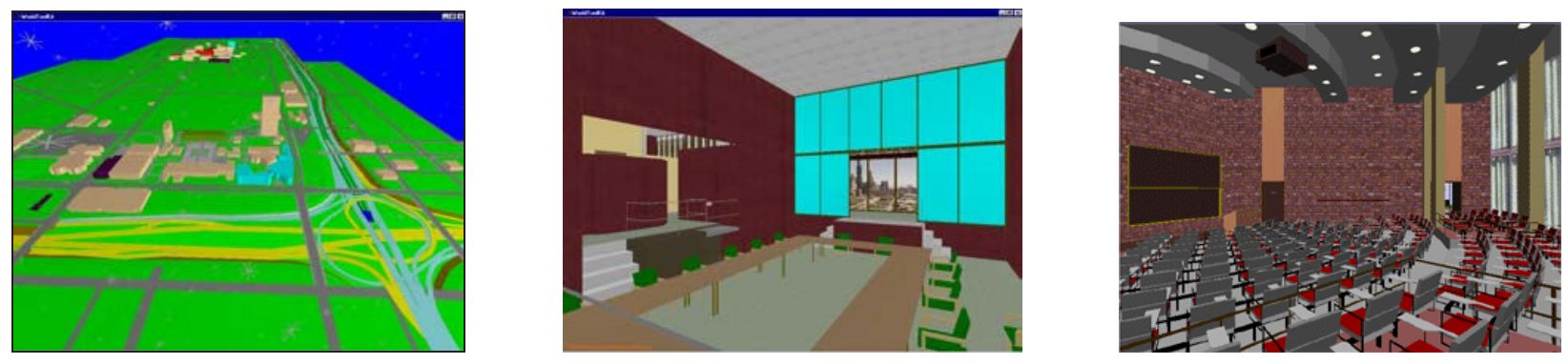

Figure 5 - Images of a Virtual Campus

\section{The Holodeck}

The Holodeck is a project that was initiated, organized, developed, and maintained almost entirely by the students involved. Initially there were three students in one of the author's courses who said that they had been working on developing a graphical environment for fun over the summer, and could they join the lab to continue the project in a more structured atmosphere ( and for some scholarly credit. ) The author agreed, and the students picked up the ball and ran with it, producing some very impressive results. (One of the things that was most impressive was the degree to which they implemented modern "best practices" of software engineering for this large and very complex project, even though none of the students involved had ever taken any courses in software engineering. The design of their classes and the relationships between them were also top-notch, long before they enrolled in the software design course. ) 

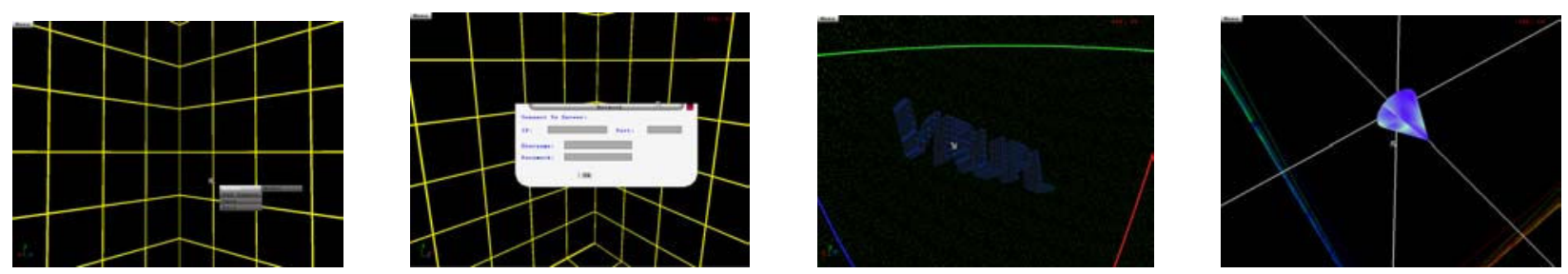

Figure 6 - Images from the Holodeck

In broad terms the Holodeck is a 3D graphical "room" bounded by gridded walls, in which users can load up objects, place cameras, and adjust viewpoints and object properties. One of the most impressive features is that it was all done in low-level $\mathrm{C}++$ and OpenGL code, without relying on any third-party libraries or development toolkits. Even the pull-down and pop-up menus were student designed and generated using low-level OpenGL code encapsulated in appropriate classes.

The original three students developed the overall class structure for the Holodeck, user interactivity, camera and view manipulation, and object loading and rendering. Other students have worked to add 3D stereoscopic display functionality, realistic physics, and network support for multi-user interactions within the Holodeck.

\section{Maintenance of Old Products}

Before the VRUPL lab was established, the author ran a similar lab at another institution, the Virtual Reality in Chemical Engineering Laboratory, VRiChEL, which developed a number of educational simulations in the area of chemical reaction and heterogeneous catalysis. These simulations are now distributed from the VRUPL laboratory, and nominally maintained, although they were all originally developed using WorldToolKit, and there are no current plans to port these old applications to a new development platform.
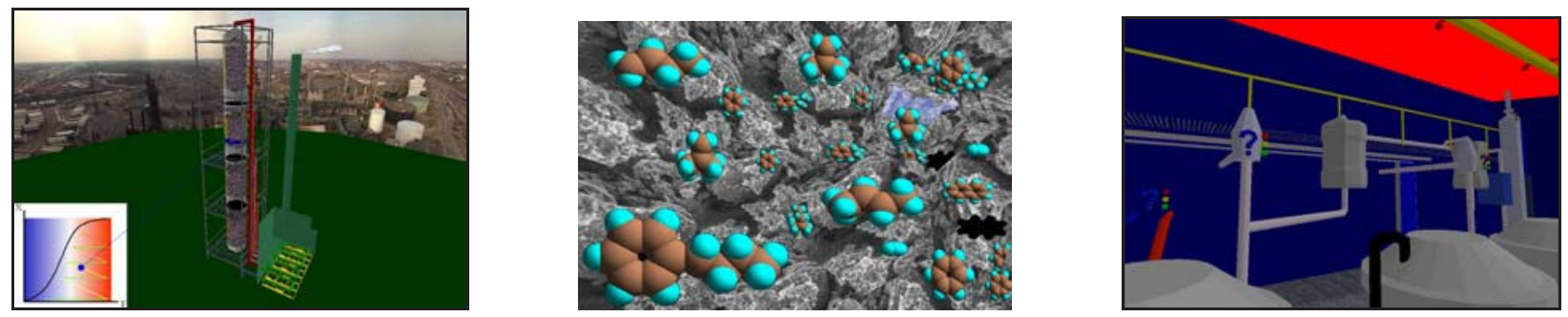

Figure 7 - Previously Developed Simulations Maintained by VRUPL

\section{Accessing the Software}

All of the software products described in this paper are either available free of charge on the VRUPL web site [7], or will be when they are completed. 


\section{EDUCATIONAL BENEFITS}

The activities of the VRUPL lab provide strong educational benefits to three major groups of constituents: the students working in VRUPL, and the students who use the products that VRUPL produces, and the lab director. The following sections explain each of these benefits.

\section{Benefits to VRUPL Students}

The VRUPL students benefit from the experience of working on large complex projects, above and beyond the scope of anything they might encounter in their normal classroom activities. ( Some of the projects have been ongoing for years, with the history being carried forward by the long-term VRUPL members. ) Both Dale Edgar's cone of learning and Kolb's work on the educational value of experience would agree that this greatly enhances their overall education. In addition, they get to collaborate with other bright energetic minds both within VRUPL and also within EVL, and they have access to advanced computers and other equipment that are not available to the general undergraduate population.

Many VRUPL students have gone on to graduate work, either at VRUPL university, ( often in the EVL laboratory), or elsewhere around the world. Others have gone on to positions in industry, including Microsoft, various computer gaming companies. One former student went on to develop interactive 3D graphic simulations for a small local chemical company. Another applied for a position that supposedly required a graduate degree even though she only had a bachelor's, and was accepted based on her work with the VRUPL lab.

\section{Benefits to the International Community}

The original VRiChEL products ( currently maintained by the VRUPL lab ) have been downloaded over 1300 times, to recipients in over 50 different countries around the globe. The virtual lab accidents have now been produced for all eight accident scenarios, on two to five platforms each, for a total of 25 different accident simulations freely available to the international community. The virtual campus products may not be as universally valuable, but they can be quite useful to students planning to attend this school from far-away lands. (A large fraction of the student body comes from either India, China, or some other foreign country. )

In addition to the values of participation and experience, VR based educational software is of particular value to visual learners and global learners on Felder and Silverman's dimensions of learning styles. ( VR allows global learners to experience educational concepts within a larger context, and to see how all the pieces fit together and interrelate. ) This type of educational software is also of benefit to active, sensory, and inductive learners.

\section{Benefits to the Lab Director}

Many faculty prefer to direct research only for graduate students ( and often only for $\mathrm{PhD}$ students ), on the grounds that they are more productive in terms of generating papers and grant proposals, and of fulfilling the grants once they are awarded. However this author has found that working with undergraduate research assistants also has great rewards. For one thing, research activities are generally optional for undergraduates, which means that the few who choose to pursue this path are generally motivated by pure interest in the subject, rather than simply 
fulfilling requirements for a degree or a stipend. ( And they also tend to be the best and the brightest. ) Secondly it allows both the student and the advisor to pursue a wide variety of academic interests, independent of any required curriculum or the boundaries and expectations of a funded grant project. Activities can be undertaken just for fun and for intellectual interest, and do not have to meet the criterion of "original scholarly work" imposed on graduate level thesis projects. And third, it can help to identify the best candidates for future graduate studies, prepare and groom them for graduate school, and then recruit them into a graduate-level research group ( before the other faculty recognize what a good catch they are. )

\section{CONCLUSIONS}

This paper has described a student projects laboratory that is relatively simple to set up and run, and which delivers important educational value to two important constituent groups: The students who work and play in the lab, and the students who use the products of the VRUPL lab. Both groups gain from the educational benefits of active participatory involvement and first-hand immersive experience. The software developed is also of particular value to visual global, active, sensory, and inductive learners on the Felder-Silverman dimensions of learning styles.

\section{ACKNOWLEDGMENTS}

The author wishes to gratefully acknowledge the efforts of the undergraduate student programmers who have assisted in the development of the projects described in this paper. Thanks are also due to Scott Fogler, Tom Defanti, Pete Nelson, John Jechura, Tom Pakula, The University of Illinois at Chicago, and others who have supported the work described here.

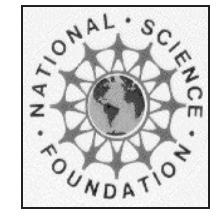

This project was supported, in part by the National Science Foundation

Opinions expressed are those of the authors and not necessarily those of the Foundation

\section{REFERENCES}

[1] Edgar, Dale, Audio-Visual Methods in Teaching. Third Edition, Holt, Rinehart, and Winston, 1969.

[2] Felder, Richard M. and L. K. Silverman, "Learning and Teaching Styles in Engineering Education", Journal of Engineering Education, 78(7), pp 674-681, 1988.

[3] Felder, Richard M., "Reaching the Second Tier - Learning and Teaching Styles in College Science Education", Journal of College Science Teaching, 23(5), pp 286-290, 1993.

[4] Kolb, D. A., Experiential Learning: Experience as the Source of Learning and Development, Prentice-Hall, Englewood Cliffs, NJ, 1984.

[5] Cruz-Neira, Carolina, Dan J. Sandin, and Thomas A. DeFanti. "Surround-Screen Projection-Based Virtual Reality: The Design and Implementation of the CAVE". Proceedings of Siggraph 93, New York, ACM Press, 1993.

[6] Czernuszenko, M., et al., "The ImmersaDesk and Infinity Wall Projection-Based Virtual Reality Displays", Computer Graphics, 31(2), pp 46-49, 1997.

[7] The Virtual Reality Undergraduate Projects Web Site", http://www.vrupl.evl.uic.edu 